\title{
Solution to Multi-axial Fatigue Life of Heterogenic Parts \& Components Based on Ansys
}

\author{
Na Wang ${ }^{1}$, Lei Wang ${ }^{2}$ \\ ${ }^{1}$ ShenyangUrban Construction University, Shenyang ,110067, China \\ ${ }^{2}$ Shenyang Yuanda Technical and Electrical Co. Ltd., Shenyang, 110067, China
}

Keywords: Heterogenic parts \& components, Hub, fatigue, Ansys

\begin{abstract}
It is very difficult to utilize traditional method for strength analysis and life calculation of heterogenic parts \& components in mechanical products. In this paper, finite element analysis software Ansys is used to analyze hub of core parts and components in wind power generator unit. Addition of external load is subject to finite element calculation, so as to work out "stress hotspot" of unit load on the hub, namely "high load area". Moreover, rain-flow counting method is used to calculate the number of times of stress circulation. According to the life curve of material, accumulative damage is calculated, and the life is determined.
\end{abstract}

\section{Introduction}

In this paper, ANSYS 11.0 finite element analysis procedure of American ANSYS Company is adopted for mechanical analysis on the hub. ANSYS software is large-scale universal finite element analysis software integrated with structure, fluid, electric field, magnetic field and sound field analysis. This software was developed by American ANSYS Company, one of the largest finite element analysis software companies in the world. It can be interfaced with most CAD software, so as to realize data sharing and exchange. It is one of advanced CAE tools among modern products.

Wind power generator unit experiences various bad weather and complicated wind alternating loads in wild for a long period of time. Its design and production involves complicated multi-disciplinary system integration technologies including mechanical manufacturing, motor, electric control, air dynamics, high molecular material and hydraulic pressure. It requires solid theoretical foundation and rich practice experience. Hub is the most key component and one of the most complicated components in wind power generator unit. Its good design, reliable quality and supreme performance are key factors guaranteeing normal and stable operation of wind generator unit as well as key and difficult points for structural design of wind generator unit. Requirements for hub: light specific gravity, good mechanical performance and fatigue strength, convenience for manufacturing and assembly, and enduring windstorm and other bad conditions and random load.

\section{Establishment of hub model}

\section{Geometric model}

Hub of a modern wind generator unit is usually casted part or component (QT400-18). Advanced casting technique can be used to produce hub featured by complicated shape, high fatigue strength and light quality. Hub is served as the connecting part of blade and spindle. Its geometrical shape and dimension are decided by blade and axis, especially for the size of hub directly decided by diameter of blade flange side and diameter of blade variable pitch bearing.

If the connecting dimension is given, the shape of hub is basically determined. The shape of hub can be roughly divided into spherical and star structure. Due to complexity of shape, finite element method is usually used for optimization design. The optimization function of finite element software is utilized to design the wall thickness and reasonably allocate the structure according to stress distribution rules of the model. Fig. 1 shows the finite element model of a company's 1.5MW hub. 


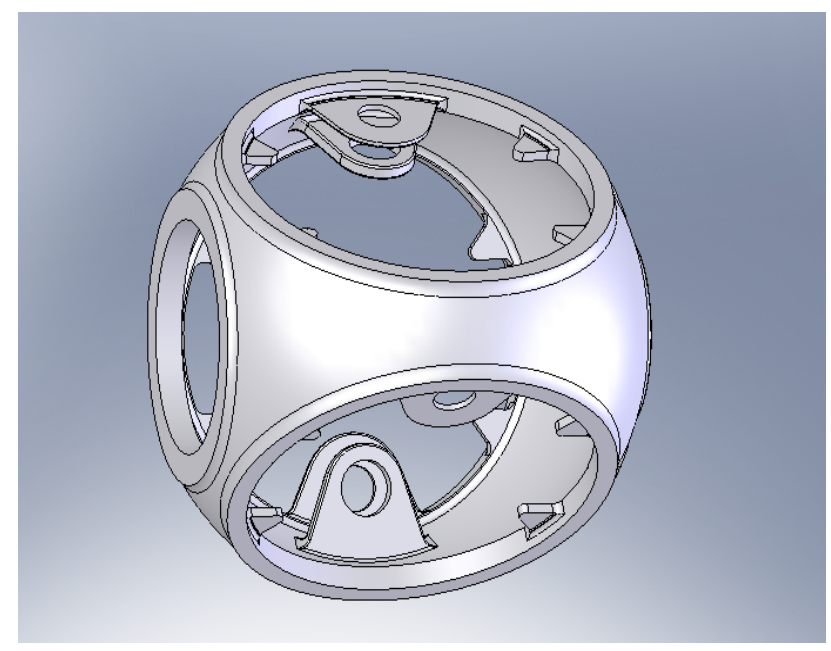

Fig. 1. Three-dimensional Hub Model of A Company’s 1.5MW Wind Power Generator Unit

\section{Coordinate system}

Fixed hub center coordinate system is adopted as global coordinate system. Local coordinate system of load adding point is converted into blade coordinate system respectively.

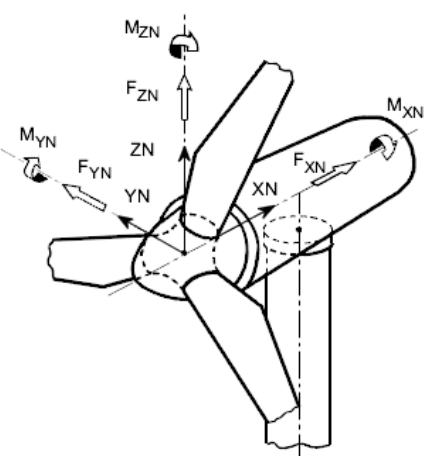

Global Coordinate System

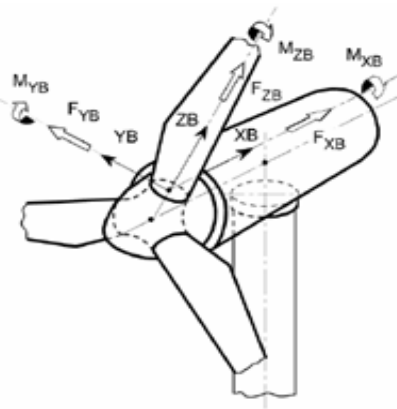

Local Coordinate System

Fig. 2. Hub Coordinate System of A Company's 1.5MW Wind Generator Unit

\section{Mesh generation}

For better control over the shape of mesh, the hub simplification model is guided into ANSYS11.0SP1 Workbench for mesh generation. The hub model is divided by hexahedral element solid186 and tetrahedron element solid187, with the result shown in Fig. 3.

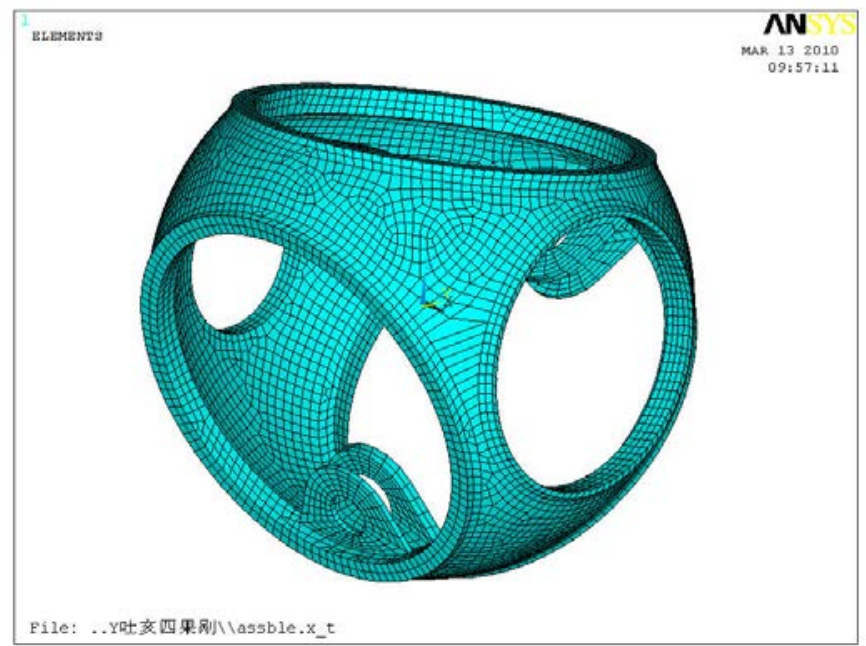

Fig. 3. Hub Finite Element Model of A Company’s 1.5MW Wind Generator Unit 


\section{Material performance parameters}

\section{Hub material}

Nodular cast iron is selected as material of hub (density: $7000 \mathrm{~kg} / \mathrm{m}^{3}$; elasticity modulus: $1.73 \times 10^{5} \mathrm{MPa}$; Poisson's ratio: 0.3 ).

Table 1. Casting - Nodular Cast Iron

\begin{tabular}{cccccc}
\hline \multirow{2}{*}{ No. } & $\begin{array}{c}\text { Wall } \\
\text { Thickness }\end{array}$ & $\begin{array}{c}\text { Tensile } \\
\text { Strength } \\
(\mathrm{MPa})\end{array}$ & $\begin{array}{c}\text { Yield Strength } \\
(\mathrm{MPa})\end{array}$ & $\begin{array}{c}\text { Elongation } \\
\text { Rate (\%) }\end{array}$ & $\begin{array}{c}\text { Hardness } \\
(\text { HBS })\end{array}$ \\
\hline \multirow{2}{*}{ Nodular cast iron } & $30<\mathrm{t}<60$ & 390 & 230 & 15 & $130-180$ \\
\cline { 2 - 5 } & $60<\mathrm{t}<200$ & 370 & 220 & 12 & 130 \\
\hline
\end{tabular}

\section{Material of other steel members}

Other structures are made of alloy structural steel (density: $7850 \mathrm{~kg} / \mathrm{m}^{3}$; elasticity modulus: $2.1 \times 10^{5} \mathrm{MPa}$; Poisson's ratio: 0.28 ).

Table 2. Data Sheet of Large-scale Forge Alloy Steel Materials

\begin{tabular}{cccccc}
\hline No. & $\begin{array}{c}\text { Tensile Strength } \\
\left(\mathrm{N} / \mathrm{mm}^{2}\right)\end{array}$ & $\begin{array}{c}\text { Yield Strength } \\
\left(\mathrm{N} / \mathrm{mm}^{2}\right)\end{array}$ & $\begin{array}{c}\text { Ballistic Work of V Groove } \\
\text { Test Rod }\left(-20 \pm 2^{\circ} \mathrm{C}\right)\end{array}$ & $\begin{array}{c}\text { Elongation } \\
\text { Rate }(\%)\end{array}$ & $\begin{array}{c}\text { Hardness } \\
(\mathrm{HB})\end{array}$ \\
\hline $\begin{array}{c}\text { Alloy structural } \\
\text { steel }\end{array}$ & $690-840$ & 460 & $27 \mathrm{~J}$ & --- & $207-255$ \\
\hline 34CrNiMo6 & $740-890$ & 540 & $31 \mathrm{~J}$ & --- & $228-269$ \\
\hline
\end{tabular}

\section{Analytical method}

\section{Analytical procedure}

Main stress on hub takes place in both time and space, making it much complex for calculation and verification. It is very difficult, especially for life calculation. Calculation with finite element method can save steps of traditional method.

Calculation steps can be simplified as follows:

(1) Through addition of external load, utilize finite element calculation to work out "stress hotspot" of unit load on the hub, namely "high load area";

(2) In these areas, calculate shear stress and normal stress for each time step of load time sequence, and determine basic stress on this basis;

(3) In a certain moment, the stress of this load in this moment can be obtained by multiplying actual load by its datum stress;

(4) Perform such calculation for all time steps in this moment, so as to obtain stress time sequence of the selected node;

(5) Select multiple nodes for calculation in the big load area, so as to obtain spatial distribution and time change of internal stress in this area;

(6) At last, use the rain-flow counting method to calculate the number of times of stress circulation, and then calculate accumulative damage and determine the life according to material life curve

Some finite element solutions are shown in the following figure.

\section{Boundary and load adding}

Prosthesis end of principal axis is completely restrained. The mode of load umbrella is used to add limit loads Fx, Fy, Fz, Mx and My onto corresponding blades and blade root notes, and restrain load adding point $\mathrm{Mz}$

Limit load 1: blade root limit load is adopted. At the same time, add loads to another two blades respectively in the center of various blade roots, adopt blade root coordinates to calculate, and impact of gravity is not considered in the calculation.

Limit load 2: when sharing part of the load (below hub rotating coordinate system) in the center of hub reaches the limit value, simultaneously add loads to the center of three blade roots, adopt blade root coordinates, and impact of gravity is not considered in the calculation. 
In total, two limit loads have 32 kinds of limit working conditions.

\section{Finite element result and analysis}

Under 32 limit working conditions, 8 kinds fail to meet strength requirements. The stress cloud picture failing to meet strength requirement is shown as follows:

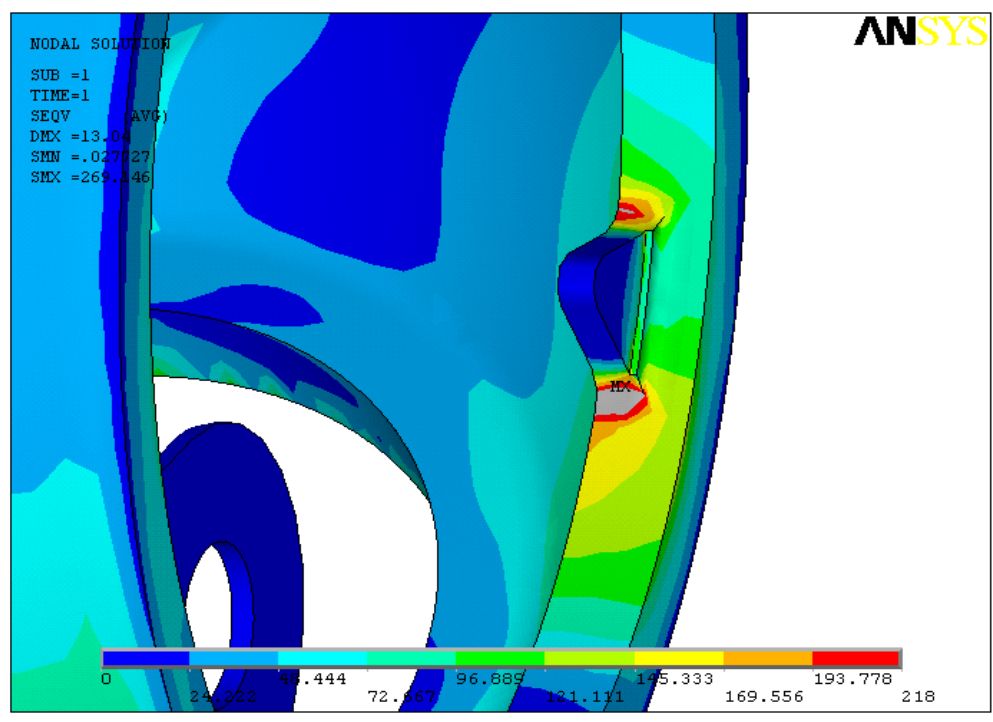

Fig. 4. Finite Element Analysis Cloud Picture under Certain Working Condition

It can be seen from the stress could picture that gray area beyond material strength is located in the corner. Such stress concentration is generated as finite element mesh generation will be deformed at this position. Therefore, the calculated stress concentration at this position is greater than actual value. It can also be seen from sectional stress cloud picture that the thickness of stress concentration gray area is much less than $1 / 5$ of hub thickness.

\section{Hub fatigue calculation}

External load of wind generator unit is loaded on a concentrated mass point, evenly delivering to the hub by the mode of rigid freedom degree coupling. For this special shape and structure of the hub, surface quality and material porosity should be considered due to impact from local opening and local support. To this end, compound fatigue life curve is usually selected to introduce the concept of survival rate and modify the material fatigue life curve.

$$
\begin{gathered}
R_{m}=1.06 R_{m}=1.06 \sigma_{0.2}=1.06 \times 240=254.4 \mathrm{MPa} \\
\sigma_{W}=0.27 R_{m}+100=168.688 \mathrm{MPa}
\end{gathered}
$$

Tensile/ bending/ distorting stress concentration factor: $\alpha \mathrm{k}=1, \mathrm{~d} \geq 100$

Stress gradient selected: $\chi^{*} \beta \mathrm{k}=\alpha \mathrm{k}=1$

$$
\begin{gathered}
F_{0}=1-\left(0.22\left(\lg R_{Z}\right)^{0.64}\right) \lg R_{m}+0.45\left(\lg R_{z}\right)^{0.53} \\
F_{0}=1-0.22 \times(\lg 100)^{0.64} \times \lg 254.4+0.45 \times(\lg 100)^{0.53}=0.825
\end{gathered}
$$

Wherein: $R_{Z}$ is the roughness of hub $(-\mu \mathrm{m})$

$$
F_{0 K}=\left(\beta_{K}^{2}-1+1 / F_{0}^{2}\right)^{0.5}=1 / F_{0}
$$

Tensile fatigue limit: $\sigma_{W K}=\sigma_{W} / F_{0 K}=168.688 \times 0.825=139.1676 \mathrm{MPa}$

Rate of fatigue S-N curve: $K=5.5 /{F_{0 K}}^{2}+6=5.5 \times 0.825^{2}+6=9.743$

Corresponding times of circulation: $\lg \left(N_{D}\right)=6.8-3.6 / K=6.8-3.6 / 9.743=6.43$

$$
N_{D}=2.69 \times 10^{6}
$$


S-N curve of finite element circulation at 50\% survival rate of EN-GJS-400-18UT is calculated above. According to relevant GL standards, the curve should be corrected, so as to obtain the infinite circulation S-N curve when the survival rate is greater than $97.7 \%$. Specific correction method is shown in Fig. 5.

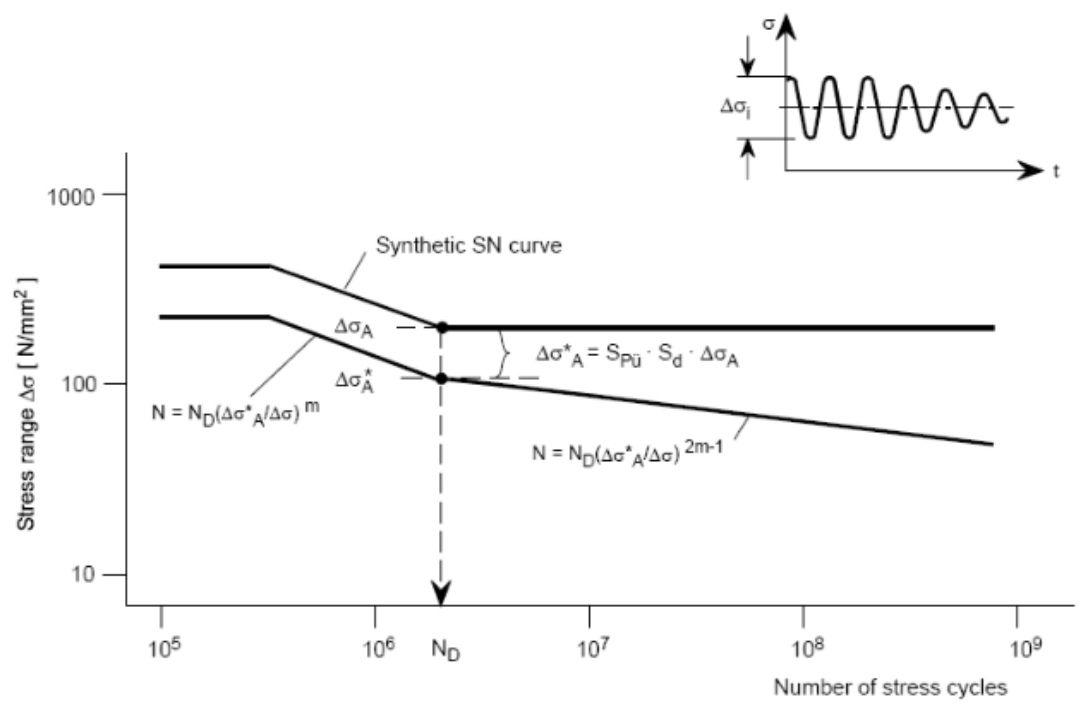

Fig. 5. Material Synthesis Fatigue Life Curve

In the figure, $\Delta \sigma_{A}^{*}=S_{\mathrm{P}_{\ddot{U}}} \cdot S_{d} \cdot \Delta \sigma_{A}, \quad S_{\mathrm{P}_{\ddot{U}}}=2 / 3$ is the reduction coefficient corresponding to the survival rate $\mathrm{P}_{\ddot{U}}>97.7 \%$. Detect impact factor $S_{d}=0.85^{\left(j-j_{0}\right)}$. Wherein: $\mathrm{j}$ is the quality grade of parts and components designed under proper strength $(\mathrm{j}=1),{ }_{0}{ }_{0}$ is constant of dependence material and testing method. According to GL ultrasonic testing, it equals to 0, therefore $S_{d}=0.85$.

According to above process, we obtain S-N curve of nodular cast iron when corrected survival rate is greater than $97.7 \%$.

\section{Conclusion}

Hub is an important part of wind generator unit. Its limit stress and fatigue stress are correlated with safe use and service life of the unit. Software Solidworks is used for modeling. After meeting relevant requirements, Ansys finite element software is used for analysis and calculation. Limit strength and fatigue strength of the hub are checked, and the following conclusions are drawn:

(1) We can know through finite element analysis method that limit strength of the hub of wind generator unit meets relevant provisions;

(2) The maximum damage result of the hub is less than 1 . Therefore, the hub meets the requirement for fatigue life.

According to the result, Ansys software can be used to minimize the design time. Expression in the pattern of picture is more direct for use to know stress of those parts and components. Moreover, obtained data can be directly used to calculate fatigue strength. The calculated result is quite accurate. Utilization of finite element method can effectively solve the multi-axial fatigue life issue of heterogenic parts \& components, improving calculation efficiency and accuracy. It is applicable to optimization design of large structural components, which can result in a better solution to the relationship between shape and load of parts and components.

\section{References}

[1] Germanischer Lloyd. Richtlinie fur die Zertifizierung von Windenergieanlagen. Hamburg, 2003

[2] Gasch R,Twele J.Windkraftanlagen. 5th ed.wiesbaden:Teuber,2007 
[3] Gasch R,Twele J.Wind Power Plants. Berlin:Solarpraxis,2002. 